\title{
A (Re)existência do Ensino de Arte sob a ótica dos docentes de Pelotas
}

\author{
A (Re) existencia de la Enseñanza de Arte bajo la óptica de los docentes de \\ Pelotas
}

\author{
The (Re) existence of Art Teaching from the point of view of the teachers of \\ Pelotas
}

Flávia Demke Rossi ${ }^{1}$

\begin{abstract}
Resumo
Esta investigação tem origem na minha pesquisa de mestrado que está em desenvolvimento no Programa de PósGraduação em Educação da UFPel. A pesquisa integra-se aos estudos sobre a docência e a formação de professores. A temática se configura como: O Ensino de Artes Visuais na contemporaneidade: Desafios, mudanças e perspectivas sob a ótica dos docentes. Busca perspectivas para a problemática de como os professores de Artes Visuais percebem sua profissão quanto aos desafios, dificuldades e mudanças. De abordagem qualitativa, a pesquisa se utiliza de entrevistas semiestruturadas com cinco professoras de Arte que atuam no Ensino Fundamental em Pelotas. Pode-se constatar uma preocupação das professoras em reafirmar a importância da Arte na escola e isto se reverbera em diferentes práticas e modos de pensar o ensino. A pesquisa possibilita a construção de ideias para uma educação que valorize os professores e que possa formar pessoas mais humanas, criativas e sensíveis para o mundo.
\end{abstract}

Palavras-Chave: Ensino de Arte; Importância da Arte/Educação; Formação de professores; Desafios e dificuldades da docência em Arte.

\section{Resumen}

Esta investigación tiene su origen en mi investigación de maestría que está en desarrollo en el Programa de Postgrado en Educación de la UFPel. La investigación se integra a los estudios sobre la docencia y la formación de profesores. La temática se configura como: La Enseñanza de Artes Visuales en la contemporaneidad: Desafíos, cambios y perspectivas bajo la óptica de los docentes. Busca perspectivas para la problemática de cómo los profesores de Artes Visuales perciben su profesión en cuanto a los desafíos, dificultades y cambios. De abordaje cualitativo, la investigación se utiliza de entrevistas semiestructuradas con cinco profesoras de Arte que actúan en la Enseñanza Fundamental en Pelotas. Se puede constatar una preocupación de las profesoras en reafirmar la importancia del Arte en la escuela y esto se ha reverberado en diferentes prácticas y modos de pensar la enseñanza. La investigación posibilita la construcción de ideas para una educación que valorice a los profesores y que pueda formar personas más humanas, creativas y sensibles para el mundo.

Palabras Clave: Enseñanza de Arte; Importancia del Arte / Educación; Formación de profesores; Desafíos y dificultades de la docencia en Arte.

\begin{abstract}
This research originates in my master's research that is under development in the UFPel Graduate Program in Education. The research is integrated with studies on teaching and teacher training. The theme is configured as: The Teaching of Visual Arts in contemporary: Challenges, changes and perspectives from the point of view of teachers. It looks for perspectives on the problem of how Visual Arts teachers perceive their profession regarding challenges, difficulties and changes. From a qualitative approach, the research uses semi-structured interviews with five Art teachers who work in Elementary School in Pelotas. One can see a concern of the teachers to reaffirm the importance of the Art in the school and this is reverbera in different practices and ways of thinking

\footnotetext{
${ }^{1}$ Mestranda em Educação pela Universidade Federal de Pelotas; Pós-Graduação em Educação - Mestrado em Educação; Pelotas, Rio Grande do Sul, Brasil; flavia.demkerossi@gmail.com
} 
the teaching. Research makes it possible to construct ideas for an education that values teachers and that can make people more human, creative and sensitive to the world.

Keywords: Art Teaching; Importance of Art / Education; Teacher training; Challenges and difficulties of teaching in Art.

\section{Introdução}

Cada profissão carrega consigo as suas dificuldades, as suas lutas, os seus estigmas sociais, as suas crenças, as suas condições de trabalho, as suas conquistas, os seus desafios e os seus ideais. Segundo Charlot (2008), o professor contemporâneo enfrenta inúmeros desafios e contradições em decorrência de transformações rápidas e profundas na sociedade. Diante disso, o professor luta por sobreviver na profissão, que lhe traz dificuldades diárias, mas também alegrias e satisfação. A busca por adaptar-se aos novos tempos, por adaptar seus conhecimentos acadêmicos à linguagem compreendida pelos jovens, por adaptar-se aos tempos escolares, às normas e as suas próprias responsabilidades como educadores.

A fim de tomar conhecimento sobre as percepções das professoras de arte sobre a importância que elas atribuem para o seu ofício, bem como, a importância que a sociedade atribui para os conhecimentos em arte, realizou-se uma pesquisa qualitativa com quatro professoras de arte da cidade de Pelotas, sendo uma delas da rede privada e as demais da rede pública de ensino. Dentre a série de questões realizadas nas entrevistas semiestruturadas, uma delas foi esta: "Qual a importância do ensino de Arte para você? ". A partir desse questionamento, as respostas das professoras, concederam pistas sobre a valorização sentida pelas professoras de Arte. Pistas que dizem respeito sobre como a arte se encontra inserida na escola, quais os espaços que dispõe, tanto físico quanto o espaço da carga horária na grade curricular.

\section{Desenvolvimento}

A respeito das percepções das professoras sobre a importância da Arte na vida dos estudantes, as respostas foram as mais variadas. Dentre elas, a construção da identidade dos estudantes, a aprendizagem do aluno em outras disciplinas, o exercício da reflexão, a aquisição de habilidades para o futuro profissional, e a compreensão da história da humanidade.

Umas das professoras de arte entrevistadas, a professora que chamaremos pelo pseudônimo de Maria, a qual leciona para o ensino fundamental em uma escola municipal de Pelotas, afirma entende que a expressividade tem grande valor nas atividades em Arte. "Eu 
acho assim, que a arte é a maneira que o aluno tem de se expressar. Às vezes dependendo do professor, do titular, talvez a aula de arte é o único momento que ele tem de expressar a área artística dele, de expressar as emoções deles. ” (PROFESSORA MARIA, 2018).

Este pensamento da professora Maria, vai ao encontro com as concepções trazidas pela Escola Nova, que foi difundido no Brasil nas décadas de 40 e 60. Segundo Ferraz e Fusari 2009, na Escola Nova o olhar voltava-se para o processo, para o método, para o aluno, seus interesses e sua espontaneidade. "O ensino de arte, portanto, direciona-se para a expressão livre da criança e o reconhecimento de seu desenvolvimento natural. " (FERRAZ E FUSARI, 2009, p. 49). A professora Maria percebe as aulas de Arte como momentos particulares para a criação e a expressão dos estudantes. Embora o saldo da "livre expressão" seja positivo, com a valorização da produção desenhista da criança, cabe desmistificar a equivocada ideia da criação artística como algo que "vem de dentro para fora", sem qualquer influência do meio. Pois na contemporaneidade há o entendimento (IAVELBERG, 2017) de que o ambiente aliado ao repertório artístico e imagético construído ao longo da vida, contribuam para as criações em Arte.

Por isso a importância de nas aulas de arte, aliar a criação e o conhecimento, não apenas sobre obras artísticas, mas ampliá-lo a fim de que a visão do aluno se alargue e perceba que os elementos que compõem a arte podem estar em seus próprios cotidianos. Para que os alunos construam um olhar estético sobre seus cotidianos e possam perceber que neles há cor, há luz, há formas geométricas, há perspectivas nas paisagens por onde transitam. Tal consciência também se transforma em conhecimento que alimenta seus repertórios imagéticos. E que lhes tornará tão útil para exprimirem-se através da arte. Quando esses aspectos são levados em consideração, a aula de arte torna-se espaço para a criatividade, para a significação dos aprendizados na vida do aluno.

Segundo Meira (2009), “As propostas de pedagogia estética e artística, [...] demandam relacionar arte e vida, onde o conhecer, o fazer, o expressar, o comunicar e o interagir instauram práticas inventivas a partir das vivências de cada um". (MEIRA, 2009, p. 122). A partir desse olhar artístico e estético para com a vida, escolhemos expressar nossas vivências, nossas subjetividades, aquilo que nos faz humanos e singulares, nosso modo de ver, de pensar e de sentir o mundo. Segundo Dewey (2010), as artes existem, por que tais significados, não conseguiriam transpor-se adequadamente em palavras pois "Há valores e sentidos que só podem ser expressos por qualidades imediatamente visíveis e audíveis, e perguntar o que eles significam em termos de algo que possa ser posto em palavras é negar sua existência distinta" (DEWAY, 2010, p. 167). 
De fato, a arte tem uma natureza distinta que se manifesta nas suas mais diversas formas de expressão e conduz nosso olhar para a compreensão de nós mesmos e do mundo que nos cerca. Como afirma a professora Maria, "E eu acredito que a arte ajuda a construir a identidade do aluno, ajuda o aluno a se interagir com ele mesmo e com o mundo, com o outro". A arte, na visão da professora, abre oportunidades para o desenvolvimento dos alunos, inclusive em outras disciplinas, "ele vai ter uma outra visão, vai ter um outro olhar" (PROFESSORA MARIA, 2018). Esta interação, falada pela professora Maria, ajuda a constituir-nos como humanos, a constituir nossa identidade. Para Meira (2009) o humano se constitui no conhecimento sensível que é gerado da interação entre o sujeito e o objeto. Para a autora, "A instauração qualitativa de interações criativas com o ambiente, a cultura, a linguagem, é responsável pelo desenvolvimento do sentido do humano em nós" (MEIRA, 2009, p.124). O que nos leva a constatação que o envolvimento e a interação entre os alunos e atividades propositivas em arte, podem contribuir na formação humana e sensível dos estudantes. Para a professora Maria, a arte oferece possibilidades maiores de “...interação com o mundo, de interação com o outro, com o público e até com a gente mesmo"(PROFESSORA MARIA, 2018). Pensamento que vai ao encontro com Dewey (2010), que reconhece a interação entre o ser vivo e o seu meio, como as raízes de toda experiência. Ela se torna consciente a partir da reflexão sobre o evento ocorrido, que resgata na memória, suas experiências passadas.

Para a professora Maria, "quando a gente está diante da arte, a gente reflete." (PROFESSORA MARIA, 2018). Tal interação, entre a obra de arte e quem a vê, seja em um cenário ideal, dentro de museus e espaço de arte, seja no cenário cotidiano da vida escolar, através de reproduções impressas ou digitais das obras de arte, é um momento que pode tornar-se uma experiência. Dewey (2010), pontua que a arte enriquece a experiência por dentro e por fora, mas isso só acontece quando nós permitimos. Ou seja, é a experiência do espectador que transforma um produto artístico criado pelo artista em uma obra de arte, e isso depende de ambos, espectador e produto artístico. Para tanto, é preciso que estejamos dispostos e suscetíveis a viver a experiência da arte.

O professor de arte tem um importante papel a desempenhar nesse sentido, pois através das atividades propostas pode conduzir seus alunos a realizarem suas próprias descobertas e ressignificações no campo artístico, de modo a valorizar a reflexão e a experiência com a arte. 
Perissé (2014) compreende a área de arte como um campo expandido onde podem ser incluídos tantos valores éticos quanto estéticos e cabe ao professor investigar e propor maneiras que ampliem pensamentos e concepções sobre a arte e a vida.

Eticamente, cabe ao docente investigar os princípios e valores (que em tese) devem orientar as ações humanas, descobrindo formas de suscitar essa reflexão entre os alunos. Esteticamente, cabe ao docente despertar em si e nos demais a reflexão sobre a arte, relacionando-a com tantos outros temas - a história, a mitologia, a política, a censura, a psicanálise, a cultura, a tecnologia, etc. (Est)eticamente cabe ao docente inventar formas belas - boas de pensar e agir, formas atraentes e inesquecíveis de atuar em sala de aula. (PERISSÉ, 2014 p.83).

A aula de arte é um espaço privilegiado para a aprendizagem que se dá através do fazer, do experimentar, do diálogo e da reflexão. Conhecimentos que também podem se encontrar com outras campos e saberes, a fim de contribuir com a formação integral dos estudantes. Para a professora Maria, o ensino de arte vai em contramão com o ato de decorar conteúdo.

Nada contra as outras disciplinas, as vezes muitas das disciplinas é decorar. Tu tem que decorar pra saber aquilo, e a arte não. Quando tu vai transmitir um conteúdo e compartilhar alguma coisa com eles, eu creio que este seja o diferencial... Da reflexão, de eles poderem interagir, de darem a opinião deles a favor ou contra. E a gente como professor, tem que ter esse leque aberto de coisas, essa aceitação. Eu não posso como professora de artes, dizer 'a arte é isso, e vocês tem que aceitar'! Não. (PROFESSORA MARIA, 2018)

Através da fala da professora Maria, nota-se que a reflexão é um valor importante para ela, que ela diz colocar em prática em suas aulas, através do diálogo com seus alunos sobre questões do mundo da arte. Uma de suas estratégias para tal, é acolher as opiniões dos estudantes sobre o que eles pensam sobre o que é arte, para que possa ser o ponto de partida para a construção dos conhecimentos através dos conteúdos.

$\mathrm{Na}$ opinião da professora Mari, é importante a abertura para o diálogo com seus alunos.

Eu acho isso para o lado positivo, para a liberdade de opiniões deles né, das opiniões, da expressão, em geral. Tudo com liberdade, mas tudo com limites, dentro das condições da escola né. Não dá para deixar eles ficarem muito livres também. Sempre interferindo quando necessário, positivamente. Mas eu creio que seja isso. (PROFESSORA MARIA, 2018)

De fato, é preciso que se estabeleça na aula de arte relações que proporcionem liberdade para ensinar, sentir, criar, refletir e aprender. De acordo com Ferraz e Fusari (2009), os objetivos da área de artes envolvem a busca pelo conhecimento da arte como cultura a fim de desenvolver as potencialidades dos educandos, como a percepção, a observação, a imaginação e a sensibilidade. 
Os conteúdos se organizam a partir do eixo norteadores de aprendizagem, a saber: produção em arte - desenvolvimento do percurso de criação pessoal; fruição apreciação significativa da arte e reflexão sobre a arte enquanto produto pessoal e pertencente a multiplicidade das culturas humanas, de todas as épocas. (FERRAZ e FUSARI, 2009 p. 58)

Tais eixos norteadores, a produção, a fruição e a reflexão sobre a arte, deveriam idealmente estarem presentes em todas as aulas de arte, a fim de estimular o desenvolvimento estético dos estudantes, através de uma aproximação que se dá através da interação com a arte. Fazer, fruir e refletir, são maneiras de nos conectarmos com o fazer artístico através das experiências que atravessam a nossa sensibilidade a fim de se tornarem conhecimentos verdadeiros.

Para tanto, são valiosas as ações em arte que integrem e valorizem o fazer, o fruir e o refletir. A professora, que usaremos o pseudônimo de Matilda, em sua prática docente realiza um trabalho com seus alunos, no qual aspectos artísticos, culturais e históricos da cidade de Pelotas são ressaltados em atividades de criação que são contextualizadas com o seu meio. Dentre as atividades relatadas pela professora, a que pude observar sua execução durante a entrevista, consistia em criar através do desenho um ladrilho hidráulico, que seria posteriormente reproduzido em argila. Em conjunto com essas atividades de natureza mais prática e criativa, a professora Matilda, contou-me que relata a seus alunos sobre como era o passado de Pelotas e como o ladrilho hidráulico se tornou parte do patrimônio artístico e cultural da cidade.

A respeito das atividades desenvolvidas, a professora Matilda relata um episódio que já foi chamada de exigente, por um de seus alunos. Em sua visão, a exigência para com o bom cumprimento das atividades propostas é algo positivo para o futuro profissional dos estudantes.

\footnotetext{
Mas eu quero isso neles, entende? Por que eu penso... Para tu ser um dentista, tu tem que fazer esse trabalho manual, essa coordenação motora fina que tu aprende na escola. Não é na faculdade que tu vai aprender a fazer um dente. É aqui moldando uma argila, fazendo trabalhos aqui”. (PROFESSORA MATILDA, 2018).
}

Ao longo do tempo, a escola, bem como o que é preciso saber e o que é preciso ensinar, também se modificam. Cada época traz a sua mentalidade e as suas ideias por vezes perduram através de gerações até serem esvaziadas, destituídas e preenchidas por novos conhecimentos, novas atitudes. É importante que nesse caminho não nos percamos na essência de educar, que a meu ver, é a vontade de formar seres mais humanos e íntegros, aptos a contribuírem para o bem da sociedade. 
Arroyo (2000), rememora o papel sensível dos educadores ao ensinar e aprender a serem seres humanos e encontrarem deste modo, o propósito de suas vidas, de seus ofícios.

\begin{abstract}
Nesse processo de redefinir o saber escolar, as funções sociais, políticas e culturais da escola em função de projetos de sociedade e de ser humano, de cidade e de cidadania não perdemos a centralidade nem do conhecimento, nem do nosso ofício de ensinar. Nos descobrimos em horizontes, intencionalidades e significados mais abertos. Reaprendemos que nosso ofício se situa na dinâmica histórica da aprendizagem humana, do ensinar e do aprender a sermos seres humanos. Por aí reencontramos o sentido educativo do nosso ofício de mestre, docentes. Descobrimos que nossa docência é uma humana docência. (ARROYO, 2000 p.53)
\end{abstract}

Nesse processo de redefinição dos saberes, e de reaprendizagem do ofício do professor em meio as estruturas dinâmicas que o sustentam, revelou uma necessidade de formação voltada para a o sensível e a integralidade do ser. Tal concepção incentiva a pensarmos a formação escolar de maneira mais ampliada. O ensino da arte segue por esta direção. Não cabem às aulas de arte somente explicações sobre artistas, obras, escolas e movimentos, mas conceder aos educandos ferramentas para tornar suas vidas obras de arte, através de um olhar reflexivo, criativo e imaginativo sobre as coisas do mundo.

Para a professora que chamaremos pelo pseudônimo de Camila, o ensino de arte "é muito importante para a criança ter uma visão maior de mundo né. Por que eles são muito limitados". No seu entendimento, a arte vai ajudar a interpretar um mapa, uma história em quadrinho, a estarem mais cientes do próprio espaço, no sentido geográfico do termo. Para isso, com seus alunos das séries iniciais (pois ela também é pedagoga) ele propõe exercícios de pintar mapas, etc. Quando se trata das aulas de arte, ela então geralmente leva as reproduções das imagens impressas com a finalidade dos estudantes manusearem e questionarem sobre as mesmas. "Eu faço atividades como, mostrar as obras e perguntar se eles já conheciam, ou o que é arte. A maioria não conhece nem os museus da cidade. Se eu vou trabalhar algum artista, já levo a obra que eu vou trabalhar. " (PROFESSORA CAMILA, 2018).

É importante que o professor realize essa observação e esse deslocamento em busca de estratégias de ensino que potencializem os conhecimentos prévios dos estudantes e ao mesmo tempo oportunizem a aquisição de novos conhecimentos sobre arte.

Em suma, para preparar e/ou desenvolver bem suas aulas, o professor que trabalha com a arte precisa conhecer as noções e os fazeres artísticos e estéticos dos estudantes e verificar em que medida podem auxiliar na diversificação sensível e cognitiva destes. Nessa concepção, se quisermos contribuir para o desenvolvimento de potencialidades do aluno, devemos planejar e orientar as atividades pedagógicas de maneira a ajudá-lo a aprender a ver, a olhar, ouvir, tocar, sentir, comparar os elementos presentes em seu mundo, tanto os da natureza como também as diferentes obras artísticas e estéticas do mundo cultural. (FERRAZ e FUSARI, 2009, p.31) 
Para a professora que chamaremos pelo pseudônimo de Flaviane, a importância do ensino de Arte é diversa. Para ela, é relevante "mostrar para o aluno o quanto a arte é importante para a nossa história, para a nossa evolução como seres humanos" (Professora Flaviane, 2018).

Para a professora Flaviane,

\begin{abstract}
Se não fosse através dos desenhos e das pinturas da arte, muita coisa não teria se desenvolvido, principalmente os estudos da ciência e da própria anatomia né, com o desenho do corpo humano. Quando na escola de Belas Artes eles dessecavam os cadáveres e desenhavam pedacinho por pedacinho do corpo humano, sempre com a questão da arte grega, que queriam mostrar a realidade perfeita do homem, o contorno do corpo, dos músculos, das veias.... Então tudo isso foi fundamental para o crescimento, para a evolução da humanidade. E também a importância né, dos primeiros documentos, dos primeiros desenhos, daí começa lá na arte rupestre, quando o homem primitivo se desenhava e desenhava o cotidiano nas paredes das cavernas e isso aí foi o primeiro registro de vida e de como acontecia isso. Tudo foi através do desenho, da pintura, então. O primeiro modo de capturar uma cena foi através da pintura, então depois de muito tempo é que veio a fotografia. Então eu acho que a arte tem tudo a ver com a nossa evolução como seres humanos. (PROFESSORA FLAVIANE, 2018)
\end{abstract}

É interessante observar o resgate histórico que a professora Flaviane realiza ao rememorar as suas aprendizagens relacionadas a história da arte a fim de valorizar momentos cruciais na relação entre arte e vida. Seu discurso busca convencermos (e certamente a seus alunos também) de que a arte pode ser entendida um produto das descobertas humanas e que tais descobertas mudaram a maneira de comunicarmos, de pesquisarmos de sermos produtores e consumidores da nossa cultura. Segundo Ferraz e Fusari (2009), o conhecimento da arte produzida em diferentes locais pelos mais diversos povos e períodos históricos, bem como outras produções do campo artístico, amplia para o educando, a sua concepção sobre a arte de um modo geral e a sua arte, as suas criações. Deste modo o educando vai desenvolvendo seu repertório cultural e apropriando-se criticamente da arte, por aprender a valorizar as criações artísticas.

A perspectiva da professora Flaviane, sobre a importância do ensino de arte, enfatiza a relação da arte com a história da humanidade e os avanços científicos. Ao lecionar em uma escola privada do município de Pelotas, a professora Flaviane, se insere em um contexto onde a competitividade do mercado exige que ela esteja constantemente comprovando sua competência e justificando suas escolhas pedagógicas sobre como e o que ensina em suas aulas de Arte. Tais escolhas, pode-se dizer que são de certa maneira socialmente condicionadas ao público de estudantes. 
A professora Flaviane, complementa ressaltando a importância de seus alunos atentarem às suas próprias sensibilidades. Para a professora,

[...] infelizmente a gente vive numa era que tudo é mais superficial, não tem muito sentimentalismo, não tem toda essa desconstrução toda. Na verdade, teve uma construção do 'eu sou forte, eu posso, eu faço do meu jeito' e é assim que funciona". (PROFESSORA FLAVIANE, 2018).

Tal afirmação leva-nos para a percepção de uma individualidade exacerbada, agravada com a tecnologia que já é uma realidade paralela ao próprio viver. Aliás vive-se as redes sociais com tamanha intensidade que esta influencia crianças, adolescentes e adultos nas suas escolhas do que se divertir, do que vestir, do que comer, para onde ir, etc. As necessidades de consumo parecem nunca estarem supridas, bem como o anseio por exibição que alimenta a competitividade nas pessoas.

Diante dessa situação, a professora Flaviane, considera importante o aspecto sensível, para ela, "tem toda essa questão do resgate da sensibilidade, que tem tudo a ver com as artes" (PROFESSORA FLAVIANE, 2018). Para exemplificar, ela parte para o campo teórico, alegando que a sensibilidade também pode se encontrar em uma análise iconológica de uma obra de arte.

Quando a gente mostra uma obra de arte também, de um determinado artista que não tem sentido, vendo a obra, ela é totalmente desconfigurada. Mas daí tu vai ler sobre a obra, ali tem a questão da expressão do artista. Tem toda uma poética, ela não foi feita do nada. Então tem toda essa questão do sentimento do que o outro quer expressar e do que ele quer mostrar (PROFESSORA FLAVIANE, 2018).

De fato, a obra de arte possui a capacidade de nos sensibilizar e mobilizar nossa cognição, que nos leva a compreensão de seus significados e intenções, que por ora fundemse às nossas interpretações e recriações sobre a mesma. São muito importantes as propostas que contribuem para o conhecimento em arte como uma das portas para a educação estética dos estudantes. O despertar para o gosto pela arte, pela sua apreciação e pela criação artística é um processo gradual, que precisa ser incentivado continuamente. O professor de arte desempenha um papel importante nesse sentido. No entanto, é preciso que ele também alimente dentro de si a sua sensibilidade estética através das manifestações artísticas e culturais.

\section{Conclusões}

É preciso, portanto, compreender o professor de arte como alguém que também se encontra em processo de construção de si, de educar-se sensivelmente para perceber melhor as qualidades artísticas que estão além das obras de arte e se encontram com a própria vida. 
Logo, também este poderá despertar nos seus alunos a vontade de manifestar-se através da arte. Bem como, contribuir para o desenvolvimento sensível e estético dos mesmos.

Em meio a estes desafios, os professores ainda enfrentam a desvalorização da educação básica, que não é propriamente salarial, mas subjetiva, colocando em cheque o valor de seu ofício para a sociedade. Percebo que tal condição é agravada quando se trata da disciplina de Artes, a qual é delegada na maioria dos casos, pouco espaço dentro do currículo, e inferior importância na hierarquia subjetiva das disciplinas escolares. Esta hierarquia também afeta a maneira como os estudantes encaram a disciplinas, as suas preconcepções que aos poucos as professoras entrevistadas estão tentando descontruir e mostrar que a arte não é apenas uma disciplina curricular, mas é conhecimento, conhecimento de si e de sua cultura, arte é pensamento imaginativo e criativo, é também um novo modo de ver o mundo cotidiano.

Não pensemos que a arte é somente uma descoberta para os alunos, pois também os professores de arte, em seus cotidianos, diante dos desafios da docência, vivem por redescobrir dentro de si o seu ofício e o seu amor pela arte, e pela criação. Embora esta não seja a criação do artista, seu trabalho não deixa de ser criativo, proponente e instigador, a fim de despertar nos estudantes a curiosidade pelo saber. A docência se reinventa a cada erro e acerto e assim vai traçando os seus caminhos, a suas estratégias de sobrevivência e de resistência.

\section{Referências}

ARROYO, Miguel G. Ofício de Mestre: imagens e autoimagens. Petrópolis: Vozes, 2000.

CHARLOT, Bernard; O professor na sociedade contemporânea: um trabalhador da contradição. In: Revista da FAEEBA - Educação e Contemporaneidade, Salvador, v.17, n.30, p.17-31, jul./dez. 2008.

GABRIEL, Perissé. Estética e Educação. Belo Horizonte: Autêntica Editora, 2009.

DEWAY, John. Arte como experiência. São Paulo: Martins Fontes, 2010

FERRAZ e FUSARI, Maria Heloísa C. de T.; Maria F. de Resende e; Metodologia do ensino de arte: fundamentos e proposições. $2^{\mathrm{a}}$ ed. São Paulo: Cortez, 2009.

IAVELBERG, Rosa; Arteleducação modernista e pós-modernista. Porto Alegre: Penso, 2017.

MEIRA, Marly Ribeiro. Filosofia da criação: Reflexões sobre o sentido do sensível. Porto Alegre: Mediação, 2009. 